\title{
Errata
}

\section{Mesorhizobium albiziae sp. nov., a novel bacterium that nodulates Albizia kalkora in a subtropical region of China}

Feng Oin Wang, En Tao Wang, Jie Liu, Qiang Chen, Xin Hua Sui, Wen Feng Chen and Wen Xin Chen

International Journal of Systematic and Evolutionary Microbiology 57, part 6, pp. 1192-1199.

In this paper, Fig. 1 parts (b) and (c) were mislabelled; Fig. 1(b) shows the tree constructed using atpD sequences (not $g / n / l$ ) and Fig. 1(c) shows the tree constructed using g/n/l sequences (not atpD).

\section{Chromobacterium aquaticum sp. nov., isolated from spring water samples}

Chiu-Chung Young, A. B. Arun, Wei-An Lai, Wen-Ming Chen, Jui-Hsing Chou, Fo-Ting Shen, P. D. Rekha and Peter Kämpfer

International Journal of Systematic and Evolutionary Microbiology 58, part 4, pp. 877-880.

The name of the fifth author in this paper was incorrectly published as Jiu-Hsing Chao. The correct spelling should be Jui-Hsing Chou.

\section{Lactobacillus ceti sp. nov., isolated from beaked whales (Ziphius cavirostris)}

\footnotetext{
A. I. Vela, A. Fernandez, A. Espinosa de los Monteros, J. Goyache, P. Herraez, B. Tames, F. Cruz, L. Domínguez and J. F. Fernández-Garayzábal.

International Journal of Systematic and Evolutionary Microbiology 58, part 4, pp. 891-894.

Lactobacillus ceti is not able to hydrolyse aesculin and therefore the result for this test presented in Table 1 on page 892 should be negative. This characteristic is correctly indicated in the species description (page 893).
} 